Prepared in cooperation with the Bureau of Reclamation

\title{
A Sampling Plan for Riparian Birds of the Lower Colorado River-Final Report
}
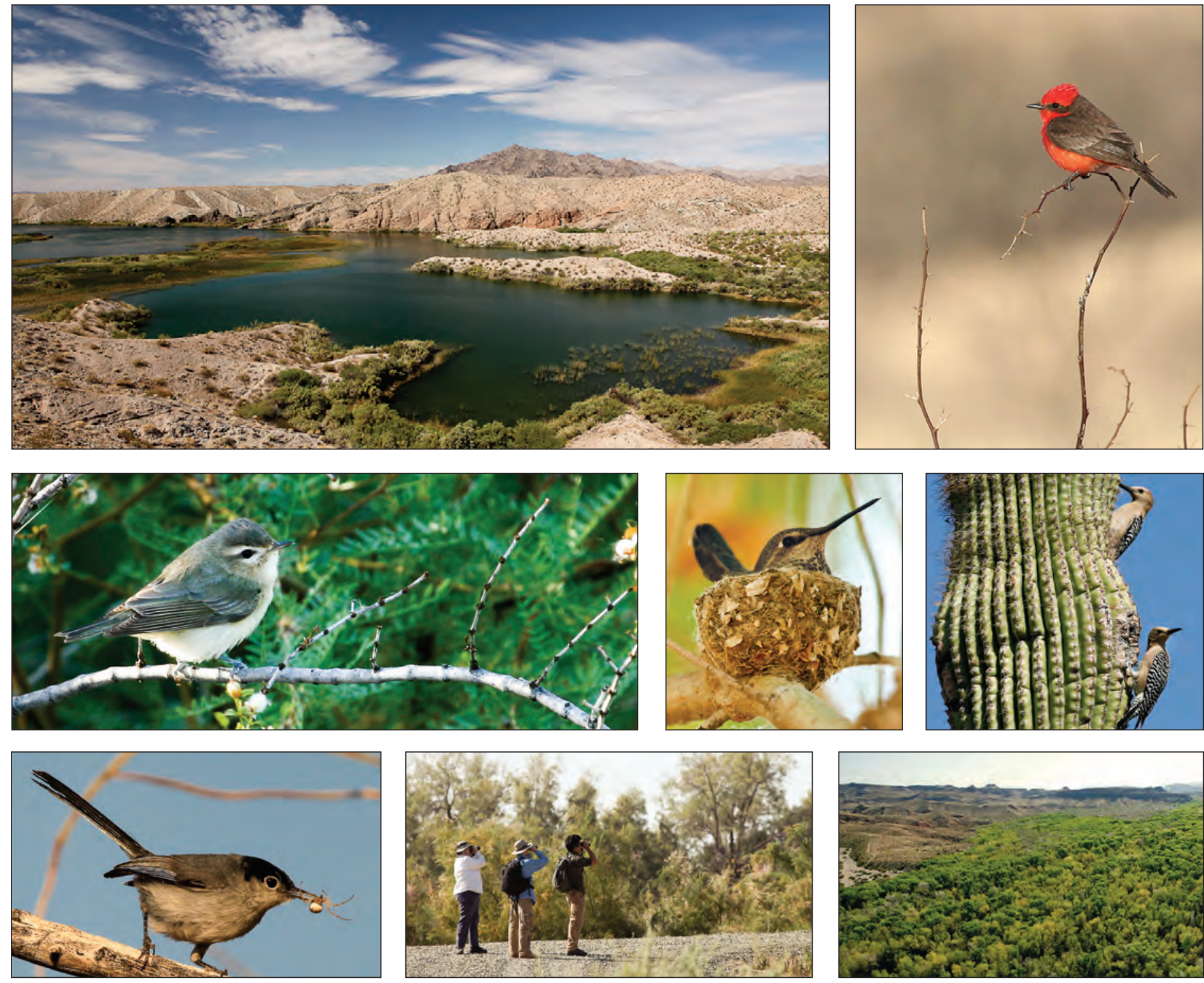

Open-File Report 2010-1158 
Cover:

Top row-left to right

Havasu National Wildlife Refuge, Arizona and California

Vermillion Flycatcher

2nd row - left to right

Bell's Vireo

Anna's Hummingbird on nest, nature trail at Cibola National Wildlife Refuge, Arizona

Gila Woodpecker pair provisioning nest in Saguaro

Bottom row-left to right

Black-tailed Gnatcatcher provisioning nest

Practice survey, Mittry Lake, Arizona

Bill Williams River National Wildlife Refuge, Arizona

All photographs were taken by Amy J. Leist, Great Basin Bird Observatory. 


\section{A Sampling Plan for Riparian Birds of the Lower Colorado River-Final Report}

By Jonathan Bart, U.S. Geological Survey; and Leah Dunn and Amy Leist, Great Basin Bird Observatory

Prepared in cooperation with the Bureau of Reclamation

Open-File Report 2010-1158

U.S. Department of the Interior

U.S. Geological Survey 


\title{
U.S. Department of the Interior \\ KEN SALAZAR, Secretary
}

\section{U.S. Geological Survey \\ Marcia K. McNutt, Director}

\section{U.S. Geological Survey, Reston, Virginia: 2010}

\author{
For more information on the USGS - the Federal source for science about the Earth, its natural and living resources, \\ natural hazards, and the environment, visit http://www.usgs.gov or call 1-888-ASK-USGS \\ For an overview of USGS information products, including maps, imagery, and publications, \\ visit http://www.usgs.gov/pubprod \\ To order this and other USGS information products, visit http://store.usgs.gov
}

\begin{abstract}
Any use of trade, product, or firm names is for descriptive purposes only and does not imply endorsement by the U.S. Government.

Although this report is in the public domain, permission must be secured from the individual copyright owners to reproduce any copyrighted materials contained within this report.
\end{abstract}

Suggested citation:

Bart, Jonathan, Dunn, Leah, and Leist, Amy, 2010, A sampling plan for riparian birds of the Lower Colorado RiverFinal Report: U.S. Geological Survey Open-File Report 2010-1158, 20 p. 


\section{Contents}

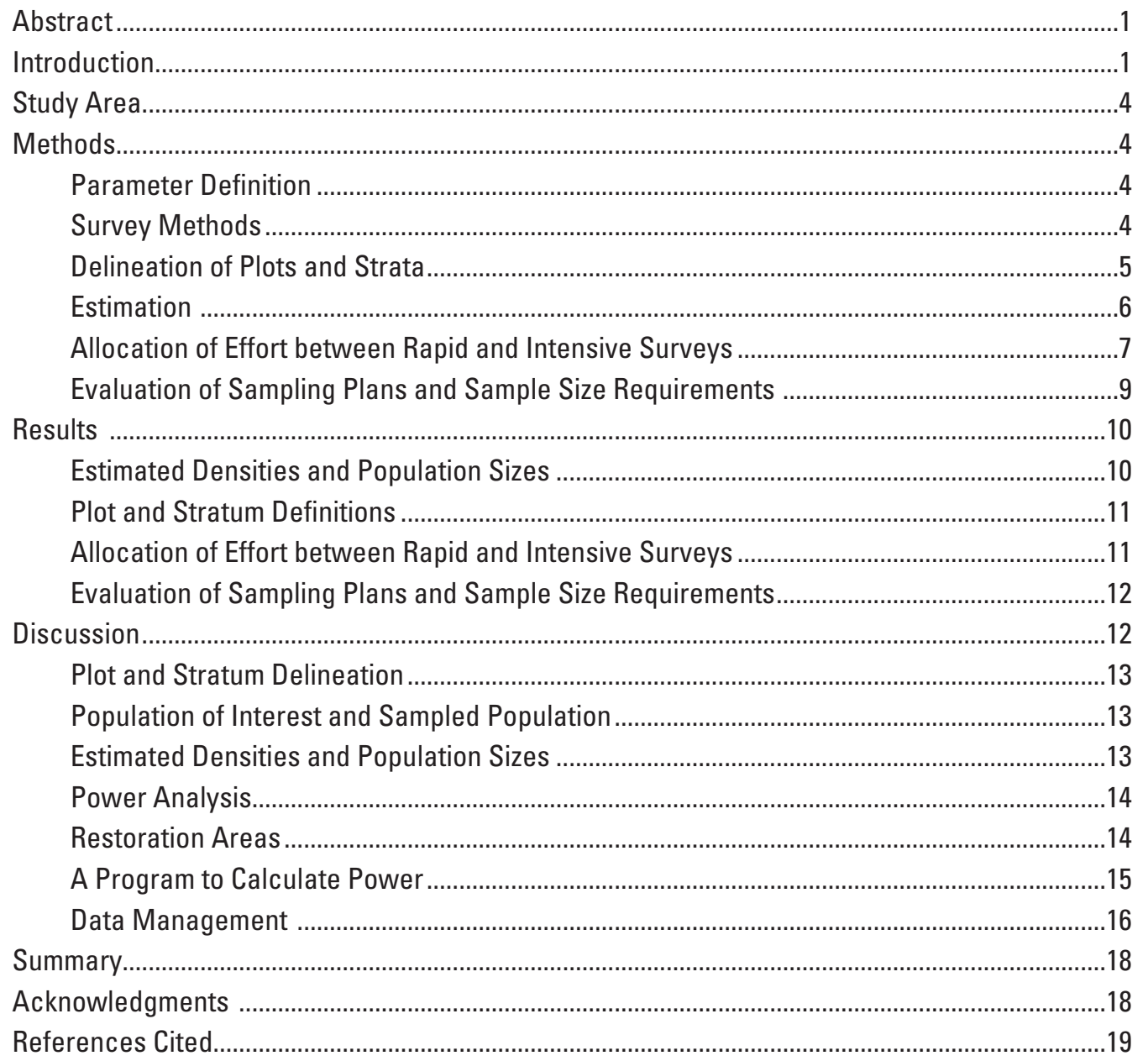




\section{Figures}

Figure 1. Map showing study area for the riparian bird surveys, Lower Colorado River, Nevada, Arizona, and California

Figure 2. Example of corrections made to original plots (all of which were square as in upper right) to concentrate high-quality habitat in as few plots as possible

Figure 3. Graphs showing simulated populations produced using Breeding Bird Survey data and used to estimate sample size requirements for the riparian bird survey.

Figure 4. Graph showing errors in rapid surveys of intensive plots 11

Figure 5. Screen in the program Power used to enter data and obtain estimated power or sample size

\section{Tables}

Table 1. Use of trend and habitat information by the Bureau of Reclamation to achieve management goals

Table 2. Habitat types used in this study starting in 2009

Table 3. Number of plots in each stratum using the classification system developed in 2009

Table 4. Species used to simulate the population of each covered species

Table 6. Example of table for analytical program, DS, specifying how to calculate detection ratios

Table 5. Numbers of indicated pairs recorded on the rapid and intensive plots ............ 10

Table 7. Detection ratios and measures of precision ................................. 11

Table 8. Estimated densities and population sizes for focal species in the study area $\ldots . . .11$

Table 9. Estimated densities and populations sizes in each habitat .................... 11

Table 10. Estimated and actual values for selected parameters used to verify the statistical method and simulation program for four focal species................ 12

Table 11. Power to detect a 50 percent decline with each of the five designs evaluated $\ldots 12$

Table 12. Power as a function of sample size when new plots are selected each year ..... 12

Table 13. Tools in the Sampling Large Landscapes extension for ArcGIS $\ldots \ldots \ldots \ldots \ldots \ldots 13$

Table 14. Power to detect population declines of 35-50 percent in 10 years in restoration

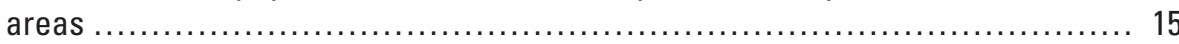

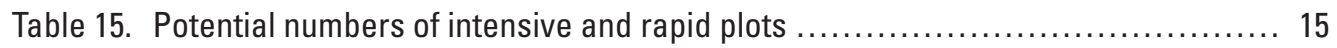




\section{Conversion Factors}

Inch/Pound to SI

\begin{tabular}{|c|c|c|}
\hline Multiply & By & To obtain \\
\hline mile (mi) & 1.609 & kilometer $(\mathrm{km})$ \\
\hline acre & 0.4047 & hectare (ha) \\
\hline acre & 0.004047 & square kilometer $\left(\mathrm{km}^{2}\right)$ \\
\hline
\end{tabular}

SI to Inch/Pound

\begin{tabular}{lcl}
\hline \multicolumn{1}{c}{ Multiply } & \multicolumn{1}{c}{ By } & \multicolumn{1}{c}{ To obtain } \\
\hline kilometer $(\mathrm{km})$ & 0.6214 & mile (mi) \\
hectare (ha) & 2.471 & acre \\
square kilometer $\left(\mathrm{km}^{2}\right)$ & 247.1 & acre \\
\hline
\end{tabular}


This page intentionally left blank. 


\title{
A Sampling Plan for Riparian Birds of the Lower Colorado River-Final Report
}

\author{
By Jonathan Bart, U.S. Geological Survey; and Leah Dunn and Amy Leist, Great Basin Bird Observatory
}

\section{Abstract}

A sampling plan was designed for the Bureau of Reclamation for selected riparian birds occurring along the Colorado River from Lake Mead to the southerly International Boundary with Mexico. The goals of the sampling plan were to estimate long-term trends in abundance and investigate habitat relationships especially in new habitat being created by the Bureau of Reclamation. The initial objective was to design a plan for the Gila Woodpecker (Melanerpes uropygialis), Arizona Bell's Vireo (Vireo bellii arizonae), Sonoran Yellow Warbler (Dendroica petechia sonorana), Summer Tanager (Piranga rubra), Gilded Flicker (Colaptes chrysoides), and Vermilion Flycatcher (Pyrocephalus rubinus); however, too little data were obtained for the last two species.

Recommendations were therefore based on results for the first four species. The study area was partitioned into plots of 7 to 23 hectares.

Plot borders were drawn to place the best habitat for the focal species in the smallest number of plots so that survey efforts could be concentrated on these habitats. Double sampling was used in the survey. In this design, a large sample of plots is surveyed a single time, yielding estimates of unknown accuracy, and a subsample is surveyed intensively to obtain accurate estimates. The subsample is used to estimate detection ratios, which are then applied to the results from the extensive survey to obtain unbiased estimates of density and population size. These estimates are then used to estimate long-term trends in abundance. Four sampling plans for selecting plots were evaluated based on a simulation using data from the Breeding Bird Survey. The design with the highest power involved selecting new plots every year. Power with 80 plots surveyed per year was more than 80 percent for three of the four species. Results from the surveys were used to provide recommendations to the Bureau of Reclamation for their surveys of new habitat being created in the study area.

\section{Introduction}

Many biological surveys of large landscapes are conducted to estimate trends in population size and to obtain estimated densities in different habitats or other subdivisions of the study area (Thompson and others, 1998; Braun, 2005; Sutherland, 2006). With widely distributed organisms, largescale stratification may provide an efficient and well-defined sampling plan. This approach is used, for example, in annual, aerial surveys to monitor waterfowl (Williams and others, 2001; U.S. Fish and Wildlife Service, 2009). In many surveys, however, some of the species of interest are concentrated into a small fraction of the landscape and they occur in small, irregularly shaped patches of habitat for example wetlands, riparian areas, and older forest. Large-scale surveys generally do not provide good estimates for species that primarily occur in these habitats. For example, the Breeding Bird Survey (BBS, Sauer and others, 2008) samples birds widely across North America but does not use habitat-based strata. It is well known that this survey does not provide good coverage of species that occur in restricted habitats (Bystrak, 1981; Droege, 1990; Rich and others, 2004). In this report, we describe methods suitable for sampling large landscapes when some of the organisms of interest occur primarily in small, irregularly shaped habitat patches.

The study was part of the Lower Colorado River MultiSpecies Conservation Program (LCR MSCP) described in detail at http://www.lcrmscp.gov/. The LCR MSCP is "a long-term plan to conserve at least 26 species along the Lower Colorado River from Lake Mead to the southerly International Boundary with Mexico through implementation of the Habitat Conservation Plan (HCP)" (Bureau of Reclamation, 2006a, p. 4). The Colorado River within this area is more than $600 \mathrm{~km}$ long and borders Nevada, Arizona, and California (fig. 1). The 26 focal species are referred to as "covered species." 


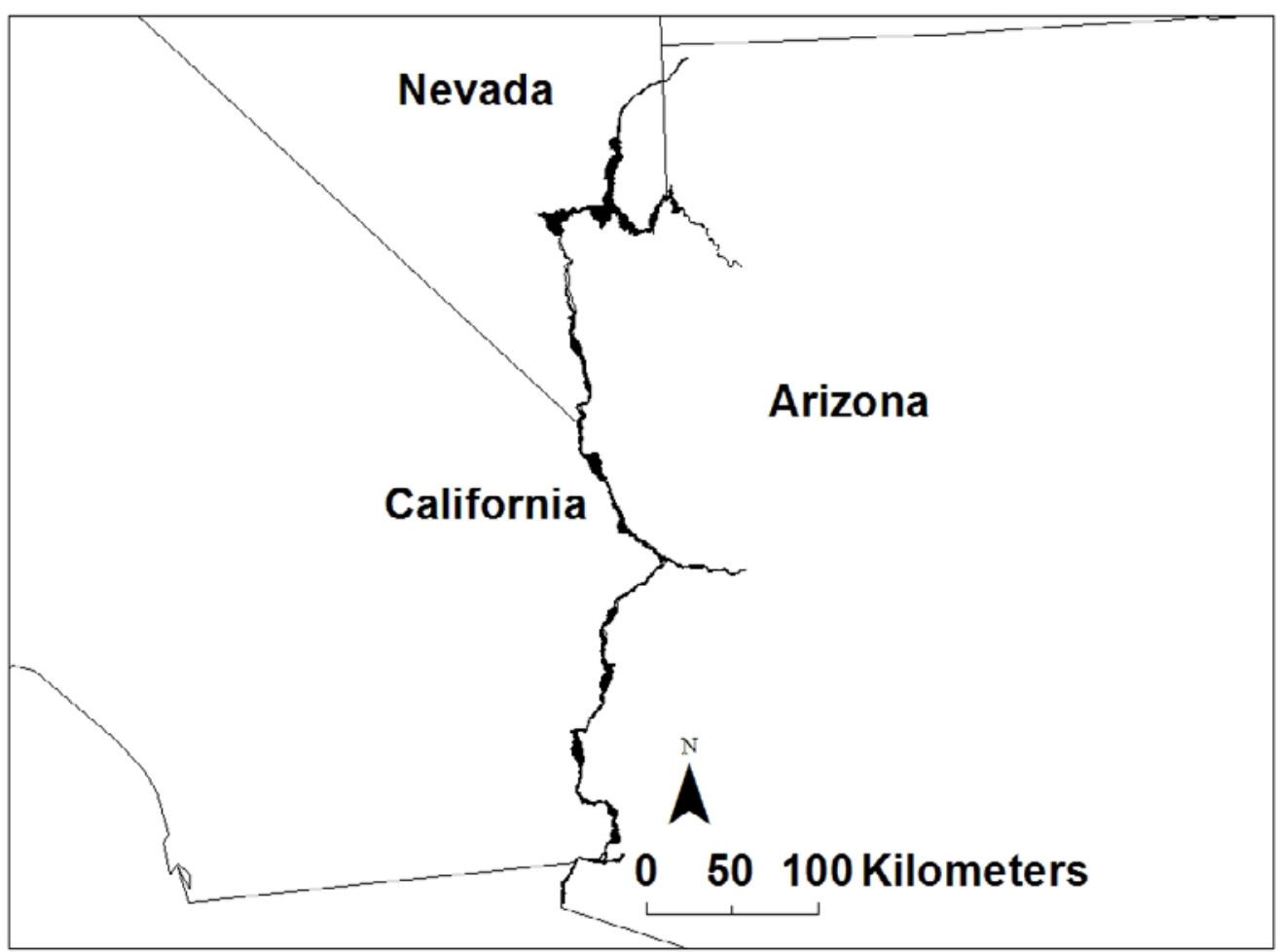

Figure 1. Study area for the riparian bird surveys, Lower Colorado River, Nevada, Arizona, and California.

The LCR MSCP divides "monitoring and research for terrestrial, riparian, and marsh habitats and associated covered species" into five "elements": (1) species research, (2) system monitoring, (3) restoration research, (4) post-development monitoring, and (5) adaptive management (Bureau of Reclamation, 2006b, p. 43-50). The purpose of system monitoring is explained in the "Science Strategy" for the LCR MSCP (Bureau of Reclamation, 2006b):

The goal of the Science Strategy's system monitoring element is to undertake monitoring necessary to determine the ongoing status of covered species and their habitats in the LCR MSCP planning area. System monitoring will provide information necessary to identify the status and trends of covered species on a regional scale and determine the contributions of created habitats to species conservation.

This description of system monitoring also notes that cooperation with other regional programs and review of monitoring and research results from elsewhere in the range may be appropriate. The section concludes by stating that "system monitoring is intended to provide a 'big picture'view of the status of covered species and their habitat that will provide Bureau of Reclamation with information necessary to help determine HCP implementation priorities and to inform the adaptive management process."

The current project addressed Work Task D6, System Monitoring for Riparian Obligate Avian Species. The purpose of this Task is to "monitor riparian obligate bird species covered under the LCR MSCP to document longterm trend and habitat use" (Bureau of Reclamation, 2006a, p. 136). "Trend and habitat use" refers to birds present during the breeding season, excluding hatching year birds (John Swett, Bureau of Reclamation, oral commun., 2008). Riparian obligate avian species include Elf Owl (Micrathene whitneyi), Yellow-billed Cuckoo (Coccyzus americanus), Gilded Flicker, Gila Woodpecker, Southwestern Willow Flycatcher (Empidonax traillii extimus), Vermilion Flycatcher, Arizona Bell's Vireo, Sonoran Yellow Warbler, and Summer Tanager. During the breeding season, Vireo bellii arizonae and Dendroica petechia sonorana are the only subspecies of Bell's 
Vireo and Yellow Warbler, respectively, found on the LCR MSCP planning area. The Southwestern Willow Flycatcher, Elf Owl, and Yellow-billed Cuckoo are being covered by other studies. This study was designed to cover the other six species listed above. They are referred to in this report as the "focal species."

We were asked to identify management objectives that the survey can help address. Through interviews and discussion, we identified the following seven objectives:

1. Features of habitat to be created.-Define target characteristics of habitats to be created for each covered species. The conservation measures in the LCR MSCP include the creation of habitat for each of the six focal species for this project. Carrying out this measure will require detailed description of the habitat to be created.

2. Location of restored areas.-Assist with determining appropriate locations for restoration areas. Knowledge of the species' distribution within the study area may be helpful during the selection of locations to be used for restoration projects. For example, two areas might be similar except that one may be much closer to a source population for one of the covered species.

3. Interpretation of results on restored areas.-Assist with interpreting results from restored areas. Response to a restoration project might be positive but weaker than expected. Surveys across the study area and surrounding areas, however, might show that populations generally were in decline.
4. Identify changes outside restored areas.-Determine whether changes are occurring elsewhere in the study area due to restoration work. Surveys throughout the study area might show that although birds occurred in the restored areas, the birds were coming from surrounding areas with no increase in the population in the study area. Alternatively, populations close to restored areas might increase due to high production within the restored areas.

5. Assess effect of large-scale changes.-Effects of largescale changes, such as water diversion or fire, can best be assessed with survey data from throughout the area.

6. Preparation of species assessments.-Help prepare species' profiles, status assessments, and other analyses of the species' health. One reason for selecting the covered species is that concern for them exists at present. In the future, status assessments for them may be needed to determine whether they warrant protection under the ESA or similar rules.

7. Revision of conservation measures.-Assist in identifying any revisions that are needed in the conservation measures. The analyses and information described above might suggest the need for a revision in the conservation measures.

All these objectives require information on suitable habitat and most of them require information on trends (table 1). Accordingly, we have given equal weight, in designing the monitoring and assessment program, to learning about habitat requirements and estimating trend in population size.

Table 1. Use of trend and habitat information by the Bureau of Reclamation to achieve management goals.

[X, useful; XX, essential]

\begin{tabular}{lccc}
\hline \multicolumn{1}{c}{ Decision, task, or issue } & $\begin{array}{c}\text { Importance } \\
\text { (1=highest) }\end{array}$ & $\begin{array}{c}\text { Description } \\
\text { of suitable } \\
\text { habitat }\end{array}$ & $\begin{array}{c}\text { Estimates } \\
\text { of trend in } \\
\text { population } \\
\text { size }\end{array}$ \\
\hline 1. Features of habitat to be created & 1 & $\mathrm{XX}$ & \\
2. Location of restored areas & 2 & $\mathrm{XX}$ & \\
3. Interpretation of results from restored areas & 1 & $\mathrm{X}$ & $\mathrm{X}$ \\
4. Identify changes outside restored areas & 2 & $\mathrm{X}$ & $\mathrm{XX}$ \\
5. Assess effect of large-scale changes & 2 & $\mathrm{X}$ & $\mathrm{XX}$ \\
6. Preparation of species assessments & 3 & $\mathrm{X}$ & $\mathrm{XX}$ \\
7. Revision of conservation measures & 2 & $\mathrm{X}$ & $\mathrm{XX}$ \\
\hline
\end{tabular}




\section{Study Area}

The study area extended from Lake Mead south along the Colorado River to the southern U.S.-Mexico border (fig. 1). Initially, the borders were defined as the Bureau of Reclamation's LCR_Veg_2004 shapefile. In 2009, the borders were modified by intersecting the vegetation layer with the MSCP boundary layer, thereby excluding portions of the vegetation layer lying outside the MSCP boundary (except along the Bill Williams River), and by excluding the areas north and east of Lake Mead.

\section{Methods}

\section{Parameter Definition}

Rigorous design of bird surveys requires that the number of birds "present" in a given area, such as a plot, be defined. It is helpful to adopt a definition under which the sum of the numbers present on all plots in the study area equals population size. If this is done, then population size can be estimated from a random sample of plots as (number of plots in the study area) times (estimated mean number of birds present per plot).

We were unable to devise a field method that would yield reliable estimates of non-territorial birds present in the study area during the breeding season. "Birds" in this study thus means "territorial birds." We used two definitions of "number present on a plot": (1) number of birds whose first nest of the season, or territory centroid for non-nesters, was within the plot (used in 2007 and 2008) and (2) sum of the fractions of the territories within the plot (used during 2009). Both definitions meet the requirement that the sum of the number present on all plots in the study area equals population size.

\section{Survey Methods}

We originally expected to use point counts to survey birds and to estimate density using distance (Buckland and others, 2001, 2004), removal (Farnsworth and others, 2002), double-observer (Nichols and others, 2000), or some other rapid method (Aldredge and others, 2007a). The vegetation, however, is often much too dense for surveyors to reach randomly selected locations (which all point count methods require for density estimation), and even if they did get to the locations, they would have little way to estimate distances to birds due to the dense vegetation (Alldredge and others, 2007b, 2008), which density estimation using any of these methods also requires. Many of the plots, however, contained paths, roads, streams, or other breaks in the dense vegetation. These corridors provided sufficient access, especially with minor pruning of the vegetation, so that area search methods, which do not require random selection of points or lines (Bibby and others, 2000), could be used. We therefore used the area search method to survey the plots. In this method, surveyors cover the entire plot, often multiple times in one visit and often on multiple visits.

Surveys started at dawn and lasted approximately 4 hours or a little later on overcast days (because birds remain active longer on overcast days). We found that surveys were most efficient with one surveyor working on one plot per morning, searching plots with no more than 12 ha of good habitat. Plots with little dense vegetations could be as many as 20 ha. Two surveys were conducted on each plot separated by at least 3 weeks. Results were combined into a single "best estimate" of the number of each species present.

Numerous factors prevented surveyors from obtaining accurate counts during the area search surveys. In dense vegetation, nearly all detections were solely by sound so if the bird did not vocalize while the surveyor was present, it was unlikely to be detected. Surveyors estimated the number of "indicated pairs" on each plot, where a pair might be indicated by a vocalizing bird or a sight record. Although females sing much less often than males, they do sing sometimes and they frequently give chip notes. Some birds also were located solely by sight, and in many species, males and females are similar or identical in appearance. Yet another difficulty in estimating the number of pairs present was that migrants were present during the first one-half of the survey period and were sometimes difficult to separate from breeders. For all these reasons, estimating the number of pairs present on a plot was difficult and frequent errors were unavoidable.

Because of the high potential for inaccurate counts on area searches, we carried out much more "intensive surveys" on a subset of the plots. Intensive surveys included at least eight visits by the same surveyor to the plot for as long as, or longer than, the "rapid" surveys. Detailed records were kept of locations of birds and indications of nesting (for example, carrying nesting material, food, or fecal sacs). At the end of the season, a final estimate was made of the number of birds present on each plot. A detailed description of the field methods is provided in Great Basin Bird Observatory (2009). 


\section{Delineation of Plots and Strata}

A land cover map with categories based on Anderson and Ohmart (1976, 1984) and Rosenberg and others (1991) was provided by the Bureau of Reclamation. We conducted a literature review of the focal species' habitat preferences, and interviewed species experts, and then consolidated these categories into six habitat types, which we called good-tall, good-low, fair, poor, marsh, and water. We expected densities of the focal species to be highest in the good-tall habitat type.

To produce the plots, we first intersected the study area with a grid of 9-ha squares. Extensive adjustments were then made to minimize the number of plots with the good-tall habitat so that the survey effort could be concentrated in this habitat type (fig. 2). In 2009, we revised the habitat definitions based on work during 2007 and 2008. The final scheme had four habitat types: tall woody, low woody, herbaceous, and unvegetated (table 2). The Anderson-Ohmart habitat types (Rosenberg and others, 1991) were tall woody: CW (1-3); low woody: CR, CW (4-6), HM, SC, SH, SM; herbaceous: AG, ATX, AW, MA; unvegetated: BW, NC, UD.

Strata were defined by assigning plots to regions and habitats. Thirteen regions were defined by the Bureau of Reclamation (table 3). The rules used in 2009 and 2010 to assign plots to habitats were:
1. If tall woody polygons cover more than 5 percent of the plot, then classify the plot as tall woody; otherwise continue to step

2. If tall woody and low woody polygons cover more than 50 percent of the plot, then classify the plot as low woody; otherwise continue to step

3. If herbaceous polygons cover more than 30 percent of the plot, then classify the plot as herbaceous; otherwise continue to step

4. If unvegetated polygons cover more than 30 percent of the plot, then classify the plot as unvegetated; otherwise assign the plot to the type that covers the largest proportion of the plot.

Table 2. Habitat types used in this study starting in 2009.

\begin{tabular}{lc}
\hline \multicolumn{1}{c}{ Type } & Primary species \\
\hline Tall woody & Cottonwood (Populus sp.) and willow \\
& (Salix sp.) largely more than 3 meters tall \\
Low woody & Cottonwood and willow largely less than \\
& 3 meters tall, mesquite (Prosopis sp.), \\
& salt cedar (Tamarix chinensis), creosote \\
& (Larrea tridenta), \\
Herbaceous & Atriplex sp., agriculture, marsh \\
Unvegetated & Bare ground, undeveloped \\
\hline
\end{tabular}

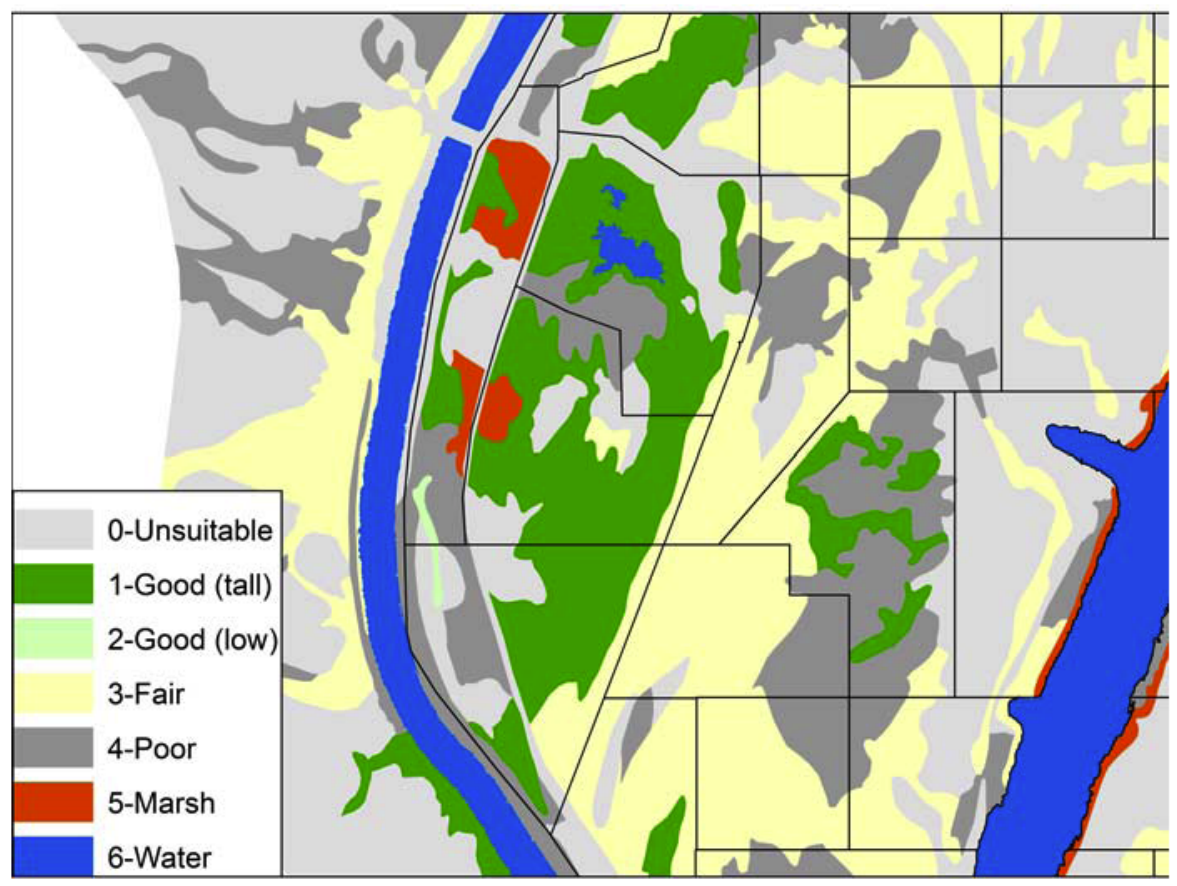

Figure 2. Example of corrections made to original plots (all of which were square as in upper right) to concentrate high-quality habitat in as few plots as possible. 
Table 3. Number of plots in each stratum using the classification system developed in 2009.

[NWR, National Wildlife Refuge]

\begin{tabular}{|c|c|c|c|c|c|}
\hline \multirow{2}{*}{ Region } & \multicolumn{4}{|c|}{ Habitat } & \multirow{2}{*}{$\begin{array}{c}\text { All } \\
\text { habitats }\end{array}$} \\
\hline & Tall woody & Low woody & Herbaceous & Unvegetated & \\
\hline 1. Separation Canyon to Lake Mead & 66 & 299 & 0 & 109 & 474 \\
\hline 2. Virgin River & 7 & 212 & 14 & 41 & 274 \\
\hline 3. Lake Mead & 0 & 844 & 0 & 656 & 1,500 \\
\hline 4. Hoover Dam to Davis Dam & 0 & 0 & 0 & 0 & 0 \\
\hline 5. Davis Dam to Bill Williams (excluding Havasu NWR) & 10 & 650 & 0 & 466 & 1,126 \\
\hline 6. Havasu NWR (excluding Bill Williams unit) & 24 & 319 & 70 & 54 & 467 \\
\hline 7. Bill Williams unit of the Havasu NWR & 50 & 301 & 0 & 343 & 694 \\
\hline 8. Bill Williams unit to Cibola excluding the Colorado Reservation & 2 & 249 & 0 & 442 & 693 \\
\hline 9. Colorado River Indian Reservation Ahakhav Preserve & 10 & 995 & 0 & 933 & 1,938 \\
\hline 10. Cibola NWR & 5 & 614 & 0 & 214 & 833 \\
\hline 11. Imperial NWR & 15 & 291 & 51 & 31 & 388 \\
\hline 12. Colorado River from the Imperial NWR to Yuma & 56 & 291 & 22 & 309 & 678 \\
\hline 13. Yuma to southern border of study area & 61 & 160 & 0 & 204 & 425 \\
\hline Total & 306 & 5,225 & 157 & 3,802 & 9,490 \\
\hline
\end{tabular}

Strata were initially constructed using all combinations of region and habitat. Some strata had only a few plots. We re-assigned the plots in these strata to similar strata with more plots except that we retained all strata with tall woody plots because that habitat is of such high interest. This process produced a plots layer with 9,490 plots assigned to 39 strata (table 3).

\section{Estimation}

The design we used is known in the survey sampling literature as double sampling. For a given species, the estimate of population density (birds $/ \mathrm{km}^{2}$ ) was

$$
d=\frac{\hat{\bar{X}}}{\hat{R}}
$$

where $\hat{\bar{X}}$ was an estimate of the density of birds that would have been recorded on rapid surveys if an indefinitely large sample of rapid surveys had been conducted and $d=\frac{\hat{\bar{X}}}{\hat{R}}$ was an estimate of the detection ratio (birds recorded/birds present) on the rapid surveys. $\hat{\bar{X}}$ was obtained from the rapid surveys; $\hat{R}$ was obtained from the intensive surveys. $V(d)$ was estimated using the standard equation for the estimated variance of a ratio of random variables (Cochran, 1977, chap. 6),

$$
\hat{V}(d)=d^{2}\left(\frac{\hat{V}(\hat{\bar{X}})}{\hat{\bar{X}}^{2}}+\frac{\hat{V}(\hat{R})}{\hat{R}^{2}}-\frac{2 \operatorname{Cov}(\hat{\bar{X}}, \hat{R})}{\hat{\bar{X}} \hat{R}}\right) .
$$

To derive estimators for the terms in expression (2), let

$U=$ number of regions,

$H=$ number of habitats,

$x_{u h i}=$ number of birds recorded on the rapid survey of the $i$ th plot of habitat $h$ in region $u$,

$a_{u h i}=$ area of the ith plot of habitat $h$ in region $u$,

$N_{u h}=$ number of plots of habitat $h$ in region $u$,

$n_{u h}=$ number of surveyed plots of habitat $h$ in region $u$,

$\hat{\bar{X}}=$ an estimate of the number of birds that would be recorded on rapid surveys if all plots in the population were surveyed, and

$a=$ an estimate of the size of the study area based on the surveyed plots. 
$\hat{\bar{X}}$ was estimated using the "combined approach" (Cochran, 1977) for ratios with stratification:

$$
\hat{\bar{X}}=\frac{\hat{X}}{a}=\frac{\sum_{u}^{U} \sum_{h}^{H} N_{u h}\left(\sum_{i}^{n_{h}} x_{u h i} / n_{u h}\right)}{\sum_{u}^{U} \sum_{h}^{H} N_{u h}\left(\sum_{i}^{n_{h}} a_{u h i} / n_{u h}\right)}=\frac{\sum_{u}^{U} \sum_{h}^{H} N_{u h} \bar{x}_{u h}}{\sum_{u}^{U} \sum_{h}^{H} N_{u h} \bar{a}_{u h}},
$$

where $\bar{x}_{u h}$ and $\bar{a}_{u h}$ are the sample means for plots of habitat $h$ in region $u$. In this study, each combination of a region and a habitat is a stratum. The basic approach, as always with stratification, is to compute separate estimates for each stratum (thus the summation across habitats, $h$, and regions, $u$ ) and then to sum the estimates.

The $V \hat{\bar{X}}$ was estimated as

$$
\hat{V}(\hat{\bar{X}})=\left(\frac{\hat{X}}{a}\right)^{2}\left(\frac{\hat{V}(\hat{X})}{\hat{X}^{2}}+\frac{\hat{V}(a)}{a^{2}}-\frac{2 C \hat{o} v(\hat{X}, a)}{\hat{X} a}\right),
$$

where

$$
\begin{gathered}
\hat{V}(\hat{X})=\sum_{u}^{U} \sum_{h}^{H} N_{u h}^{2}\left[s^{2}\left(x_{u h i}\right) / n_{u h}\right], \\
\hat{V}(a)=\sum_{u}^{U} \sum_{h}^{H} N_{u h}^{2}\left[s^{2}\left(a_{u h i}\right) / n_{u h}\right],
\end{gathered}
$$

and

$$
\operatorname{Cov}(\hat{X}, a)=\sum_{u}^{U} \sum_{h}^{H} \frac{N_{u h}^{2}}{n_{u h}} \operatorname{Cov}\left(x_{u h i}, a_{u h i}\right) .
$$

The other terms in expression (4) are defined in expressions $(1-3) ; s^{2}$ and $C \hat{v} v$ indicate the sample variance and covariance, respectively.

The detection ratio, $R$, was estimated as

$$
\hat{R}=\frac{\bar{x}}{\bar{y}},
$$

where

$\bar{x}$ was the mean number of birds recored on rapid surveys of the intensive plots, and

$\bar{y}$ was the mean number of birds determined to be present on these plots through intensive surveys.
The variance of $\hat{R}$ was estimated as

$$
\hat{V}(\hat{R})=\hat{R}^{2}\left(\frac{\hat{V}(\bar{x})}{\bar{x}^{2}}+\frac{\hat{V}(\bar{y})}{\bar{y}^{2}}-\frac{2 \operatorname{Co} v(\bar{x}, \bar{y})}{\overline{x y}}\right)
$$

where

$$
\begin{aligned}
& \hat{V}(\bar{x})=\frac{1}{m} s^{2}\left(\bar{x}_{i}\right), \quad \hat{V}(\bar{y})=\frac{1}{m} s^{2}\left(\bar{y}_{i}\right), \\
& \operatorname{Cov}(\bar{x}, \bar{y})=\frac{1}{m} \operatorname{cov}\left(\bar{x}_{i}, \bar{y}_{i}\right)
\end{aligned}
$$

The estimated population size was

$$
\hat{Y}=A d,
$$

where

$A$ was the size of the study area.

where $A$ was the size of the study area. The variance of $\hat{Y}_{\text {was }}$ estimated as

$$
\hat{V}(\hat{Y})=A^{2} \hat{V}(d) .
$$

A windows program named DS was prepared to analyze data collected using double sampling. DS produces species-specific estimates of density in each stratum (region-habitat combination) and estimates of population size in each region. All estimates are accompanied by an estimated standard error (SE) or coefficient of variation (CV).

\section{Allocation of Effort between Rapid and Intensive Surveys}

Two allocation of effort issues arise in this sampling plan: how to subdivide the rapid surveys among strata, and how to subdivide effort between rapid and intensive surveys. Ideally, we would address both problems with respect to trend estimation, however, this would require more accurate estimates than we are able to obtain. Instead, we based recommendations on maximizing precision of the estimated population sizes within years.

The analytic methods for allocating rapid surveys among strata (Cochran, 1977) require variances within strata that we did not have sufficient sample sizes to estimate. We therefore used a simple approach based on the principles of optimal allocation. We calculated initial sample sizes so that the same proportion of plots would be surveyed in each stratum. We then adjusted sample sizes (without changing the total number of rapid plots), increasing the plots in strata expected to have more birds (based on the assumption that the within-stratum variance in these plots would be higher) and decreasing the plots in strata that were difficult to reach. 
For the second issue, allocation of effort between rapid and intensive surveys, we derive the formula for the number of rapid plots, with fixed total costs, that minimizes $\mathrm{CV}(d)$. We assume that costs for rapid and intensive plots may each be viewed as a fixed cost plus a variable cost that is a constant times the number of plots. Let

$\alpha_{r}=$ fixed cost for rapid plots,

$\beta_{r}=$ variable cost for rapid plots,

$\alpha_{i}=$ fixed cost for intensive plots,

$\beta i=$ variable cost for intensive plots,

$n_{r}=$ number of rapid plots,

$n_{i}=$ number of intensive plots.

Then total cost, $C^{*}$, is

$$
C^{*}=\left(\alpha_{r}+\beta_{r} n_{r}\right)+\left(\alpha_{i}+\beta_{i} n_{i}\right) .
$$

The fixed costs do not influence the allocation of effort between rapid and intensive plots (assuming that at least one intensive plot is surveyed), so it is convenient to write

$$
\begin{gathered}
C=C^{*}-\alpha_{r}-\alpha_{i}=\beta_{r} n_{r}+\beta_{i} n_{i} . \\
n_{i}=\frac{C-\beta_{r} n_{r}}{\beta_{i}} .
\end{gathered}
$$

Now, expression (2), because we are assuming zero covariance between $\bar{X}$ and $\hat{R}$, may be written

$$
\begin{aligned}
\hat{V}(d) & =d^{2}\left(\frac{\hat{V}(\hat{\bar{X}})}{\hat{\bar{X}}^{2}}+\frac{\hat{V}(\hat{R})}{\hat{R}^{2}}\right) \equiv d^{2}\left(\frac{G_{r}}{n_{r}}+\frac{G_{i}}{n_{i}}\right) \\
& =d^{2}\left(\frac{G_{r}}{n_{r}}+\frac{\beta_{i} G_{i}}{C-\beta_{r} n_{r}}\right)
\end{aligned}
$$

Defining $G_{r}$ and $G_{i}$ lets us separate the sample sizes, $n_{r}$ and $n_{i}$, from the quantities that do not depend on sample size. To derive $G_{r}$, let $f_{u h}=n_{u h} / n_{r}$ so that $n_{u h}=n_{r} f_{u h}$. Then expression (4), may be written

$$
\begin{aligned}
V(\hat{\bar{X}}) & =\frac{\hat{\bar{X}}^{2}}{n_{r}} \frac{\sum_{u}^{U} \sum_{h}^{H} N_{u h}^{2} s^{2}\left(x_{u h i}\right) / f_{u h}}{\hat{X}^{2}}+\frac{\sum_{u}^{U} \sum_{h}^{H} N_{u h}^{2} s^{2}\left(a_{u h i}\right) / f_{u h}}{\hat{A}^{2}} \\
& -\frac{2 \sum_{u}^{U} \sum_{h}^{H} N_{u h}^{2} \operatorname{Cô}\left(x_{u h i}, a_{u h i}\right) / f_{u h}}{\hat{X} \hat{A}}
\end{aligned}
$$

and therefore

$$
\begin{aligned}
G_{r}= & \frac{\sum_{u}^{U} \sum_{h}^{H} N_{u h}^{2} s^{2}\left(x_{u h i}\right) / f_{u h}}{\hat{X}^{2}}+\frac{\sum_{u}^{U} \sum_{h}^{H} N_{u h}^{2} s^{2}\left(a_{u h i}\right) / f_{u h}}{\hat{A}^{2}} \\
& -\frac{2 \sum_{u}^{U} \sum_{h}^{H} N_{u h}^{2} \operatorname{Cov}\left(x_{u h i}, a_{u h i}\right) / f_{u h}}{\hat{X} \hat{A}}
\end{aligned}
$$

Similarly, because the intensive plots are a one-stage sample, expression (6) may be written as

$$
V(\hat{R})=\frac{\hat{R}^{2}}{n_{i}}\left(\frac{s^{2}\left(x_{i}\right)}{\bar{x}^{2}}+\frac{s^{2}\left(y_{i}\right)}{\bar{y}^{2}}-\frac{2 \operatorname{Cov}\left(x_{i}, y_{i}\right)}{\overline{x y}}\right)
$$

so

$$
G_{i}=\frac{s^{2}\left(x_{i}\right)}{\bar{x}^{2}}+\frac{s^{2}\left(y_{i}\right)}{\bar{y}^{2}}-\frac{2 \operatorname{Cov} v\left(x_{i}, y_{i}\right)}{\overline{x y}} .
$$

We used expressions (13) and (14) to calculate $G_{r}$ and $G_{i}$.

The next step is to choose the value for $n_{r}$ that minimizes $\mathrm{V}(d)^{2}$ or, equivalently, from expression (12), that minimizes $G_{r} n_{r}^{-1}+\beta_{i} G_{i}\left(C-\beta_{r} n_{r}\right)^{-1}$. Taking the derivative with respect to $n_{r}$, setting it equal to 0 , and solving for $n_{r}$ yields

$$
n_{r}=\left(\frac{C}{\beta_{r}}\right)\left(\frac{1-\sqrt{\chi}}{1-\chi}\right)
$$

where

$$
\chi=\frac{\beta_{i} G_{i}}{\beta_{r} G_{r}} .
$$

Note from expression (15), that the proportion of days devoted to rapid surveys is $(\sqrt{\chi}+1) /(\chi-1)$. Expression (15) was used to calculate the recommended number of rapid plots for fixed total cost. Expression (11) was then used to obtain the number of intensive plots.

Two practical problems arise in estimating $\mathrm{G}_{r}$ and $G_{i}$. One is that their values vary from species to species but obviously, there can only be one allocation of effort between rapid and intensive plots. The other problem is that the estimates may be influenced substantially by sampling error, especially with the relatively small samples typical of pilot studies. We therefore estimated $G_{r}$ and $G_{i}$ by combining results from all focal species. This yielded a single estimate so we did not have to choose from several, species-specific estimates, and the effects of sampling error were reduced by the larger number of birds in the plots. 


\section{Evaluation of Sampling Plans and Sample Size Requirements}

We investigated sample size requirements by simulating populations of the covered species in the study area and then sampling repeatedly from them. We investigated sample sizes required to give at least 80 percent power of detecting a 50 percent decrease in population size that occurred during 20 years. Reasons for adopting these parameters are discussed by Bart and others (2004). Both the landbird and shorebird initiatives have adopted the " 50 percent decrease in population in 20 years" standard (Skagen and others, 2003; Bart and others, 2004).

The simulated population had a number of birds in each plot in the LCR study area in each of 20 years. Population size decreased approximately 50 percent during the 20 years. We used the simulated population to evaluate different sampling plans and to estimate the sample size needed to achieve the accuracy target.

Because we had only a few years of survey data for the study area, we had to use a surrogate dataset to create the simulated survey. The BBS is well-suited for this task because it is a long-term survey, includes several thousand routes, and records the same species we are studying. We therefore used data from the BBS (collected during 1989-2008) to create the simulated population. We found, however, that on the BBS, the covered species were not recorded often enough in the large numbers that were recorded on the riparian bird surveys. For example, 20+ Bell's Vireos were recorded on four plots in our study area indicating that dozens of plots in the simulated population needed to have this many Bell's Vireo. But 20+ Bell's Vireos were only recorded regularly on four plots in the BBS during 1989-2008. One of these routes was not surveyed in 6 years and the sum of the numbers counted on the other three routes did not show any clear change during 1989-2008. These routes thus did not provide a good basis for simulating a population with counts of $20+$ birds and in which population size decreased 50percent. The underlying problem was that we needed many more BBS routes with large numbers recorded. We obtained such a dataset by including other species (table 4). Sufficient data were available from the BBS for Yellow Warblers so that we did not need to use data from other species. We used data from two to four additional species for Gila Woodpeckers, Bell's Vireos, and Summer Tanagers. The other two focal species, Gilded Flickers and Vermilion Flycatchers, were seldom recorded on our surveys so we did not carry out simulations for those two species.

The simulated populations were created by identifying the 1,376 BBS routes that were surveyed at least 16 times during 1999-2008 (20 years). These routes were located throughout the area covered by the BBS (the lower 48 States and southern Provinces in Canada). A missing data procedure was used to fill in the missing counts. States were then selected in which a pronounced trend occurred. If the trend was positive, the columns were reversed. Routes were then assigned to plots in the simulated population based on the distribution of numbers present in the stratum. This procedure produced four populations in which population size decreased by approximately 50 percent in 20 years (fig. 3 ).

Table 4. Species used to simulate the population of each covered species.

\begin{tabular}{ll}
\hline \multicolumn{1}{c}{ Focal species } & \multicolumn{1}{c}{ Species used in the simulation } \\
\hline Gila Woodpecker & Gila Woodpecker, Ladder-backed Woodpecker, Northern Flicker \\
Bell's Vireo & Bell's, Gray, Hutton's, Plumbeous, and Warbling Vireos \\
Yellow Warbler & Yellow Warbler \\
Summer Tanager & Summer, Hepatic, and Western Tanagers \\
\hline
\end{tabular}
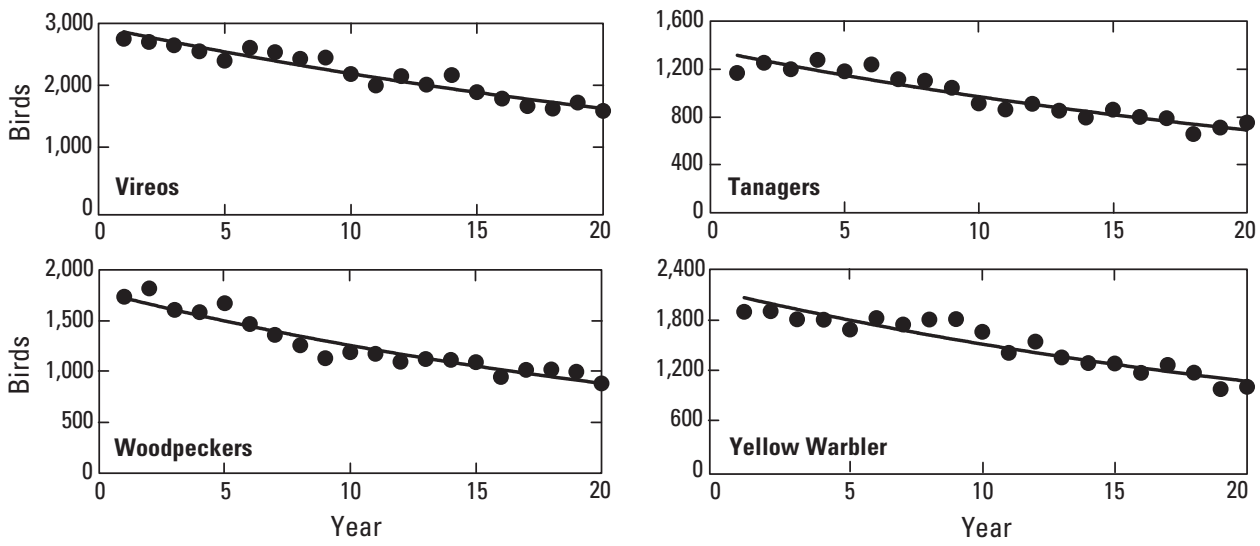

Figure 3. Simulated populations produced using Breeding Bird Survey data and used to estimate sample size requirements for the riparian bird survey. 
We then developed a computer program that sampled from the simulated population during some or all of the 20 years, calculated the estimated population size in each year the survey was conducted, estimated the 20 -year trend using an exponential curve, and estimated the SE of the trend using the bootstrap method (Efron and Tibshirani, 1993; Shao, 2003). The program repeated this process a large number of times and reported the average trend estimate, the average SE, the actual SE among the simulations, and the proportion of cases in which the trend estimate was significantly less than 1 (that is, power). The output allowed us to verify the estimated trend and its SE as well as determining power for different sampling plans.

We investigated five designs. In the first design, one set of 40 plots was visited every year and three other, 40-plotsets were each visited every third year (that is, a panel design; Urquhart and Kincaid, 1999). In the second design, a new sample of 80 plots was selected each year (so there were 20 sets of plots). In the third design, a single set of 80 plots was re-visited each year. We also evaluated the second and third designs but with surveys conducted in alternate years. We investigated the needed sample size by determining power for sample sizes of 40 to 120 . Allocation of plots to strata was determined by management objectives (for example, having estimates from each part of the study area), rather than by a desire to maximize precision of the area-wide trend estimate, so we did not explore different allocations of effort.

\section{Results}

\section{Estimated Densities and Population Sizes}

During 2007-09, we conducted rapid surveys on 247 plots and intensive surveys on 33 plots. We recorded 912 indicated pairs of the covered species on rapid plots and 155 on intensive plots (table 5). Gila Woodpeckers, Bell's Vireo, and Yellow Warblers were recorded most often. Summer Tanagers were recorded much less often, and Gilded Flickers and Vermilion Flycatchers were hardly ever recorded.

The first step in the analysis was deciding how to calculate detection ratios. The analytical program, DS, permits the user to specify that any group of species will be used to
Table 5. Numbers of indicated pairs recorded on the rapid and intensive plots.

\begin{tabular}{lrc}
\hline \multirow{2}{*}{\multicolumn{1}{c}{ Species }} & \multicolumn{2}{c}{ Plots } \\
\cline { 2 - 3 } & Rapid & Intensive \\
\hline Gila Woodpecker & 167 & 27 \\
Gilded Flicker & 0 & 0 \\
Vermilion Flycatcher & 7 & 0 \\
Bell's Vireo & 358 & 57 \\
Yellow Warbler & 316 & 64 \\
Summer Tanager & 64 & 7 \\
$\quad$ Totals & 912 & 155 \\
\hline
\end{tabular}

estimate the detection ratio for each species. The instructions are contained in a table that has one row and one column for each species (table 6). The table is best explained by examples from table 6 . In calculating the estimated detection ratio for Gila Woodpeckers (first row in table 6), DS would only use data from Gila Woodpeckers because that is the only column with a "1." In contrast, no Vermilion Flycatchers were present on intensive plots (although 7 were recorded on rapid surveys of other plots) so their detection ratio obviously cannot be calculated without using data from other species. Table 6 contains instructions on how to direct DS to use data for Bell's Vireo and Yellow Warblers (a "1" also is entered in the Vermilion Flycatcher column by default).

Species-specific detection ratios were very similar for Gila Woodpeckers, Bell's Vireo, and Yellow Warbler and the SEs indicated that differences were far from significant (table 7). We therefore used a single combined detection ratio (that is, table 6 was filled with 1s). The detection ratio for all species combined was 1.05. Although the average was close to 1, errors on individual plots were often substantial (fig. 4) especially on plots with lots of birds present. Errors for individual species were even larger. Therefore, it should not be assumed that rapid surveys yield estimates of high accuracy at the level of individual plots.

Estimated densities and population sizes were $12-18$ birds $/ \mathrm{km}^{2}$ and $13,000-19,000$ birds, respectively, for the three common species (table 8). CVs were 0.22-0.24.

Estimates were much lower, and CVs were much higher, for the other species.

Table 6. Example of table for analytical program, $D S$, specifying how to calculate detection ratios.

\begin{tabular}{lccccc}
\hline \multicolumn{1}{c}{ Species } & $\begin{array}{c}\text { Gila } \\
\text { Woodpecker }\end{array}$ & $\begin{array}{c}\text { Vermilion } \\
\text { Flycatcher }\end{array}$ & $\begin{array}{c}\text { Bell's } \\
\text { Vireo }\end{array}$ & $\begin{array}{c}\text { Yellow } \\
\text { Warbler }\end{array}$ & $\begin{array}{c}\text { Summer } \\
\text { Tanager }\end{array}$ \\
\hline Gila Woodpecker & 1 & 0 & 0 & 0 & 0 \\
Vermilion Flycatcher & 0 & 1 & 1 & 1 & 0 \\
Bell's Vireo & 0 & 0 & 1 & 0 & 0 \\
Yellow Warbler & 0 & 0 & 0 & 1 & 0 \\
Summer Tanager & 1 & 0 & 0 & 1 & 1 \\
\hline
\end{tabular}


Table 7. Detection ratios and measures of precision.

\begin{tabular}{lccc}
\hline \multicolumn{1}{c}{ Species } & $\begin{array}{c}\text { Detection } \\
\text { ratio }\end{array}$ & $\begin{array}{c}\text { Standard } \\
\text { error } \\
\text { (SE) }\end{array}$ & $\begin{array}{c}\text { Coefficient } \\
\text { of variation } \\
\text { (CV) }\end{array}$ \\
\hline Gila Woodpecker & 1.04 & 0.28 & 0.27 \\
Bell's Vireo & 0.98 & 0.09 & 0.10 \\
Yellow Warbler & 0.98 & 0.17 & 0.18 \\
Summer Tanager & 2.00 & 0.62 & 0.31 \\
\cline { 2 - 4 }$\quad$ Combined & 1.05 & 0.12 & 0.12 \\
\hline
\end{tabular}

Table 8. Estimated densities and population sizes for focal species in the study area.

$\left[\mathrm{km}^{2}\right.$, square kilometer $]$

\begin{tabular}{lrrc}
\hline \multicolumn{1}{c}{ Species } & $\begin{array}{c}\text { Density } \\
\text { (birds/km²) }\end{array}$ & $\begin{array}{c}\text { Population } \\
\text { size }\end{array}$ & $\begin{array}{c}\text { Coefficient } \\
\text { of variation } \\
\text { (CV) }\end{array}$ \\
\hline Gilded Flicker & 0.00 & 0 & - \\
Gila Woodpecker & 12.34 & 13,326 & 0.22 \\
Vermilion Flycatcher & 0.84 & 902 & 0.75 \\
Bell's Vireo & 17.56 & 18,982 & 0.24 \\
Yellow Warbler & 15.94 & 17,218 & 0.23 \\
Summer Tanager & 3.46 & 3,736 & 0.34 \\
\hline
\end{tabular}

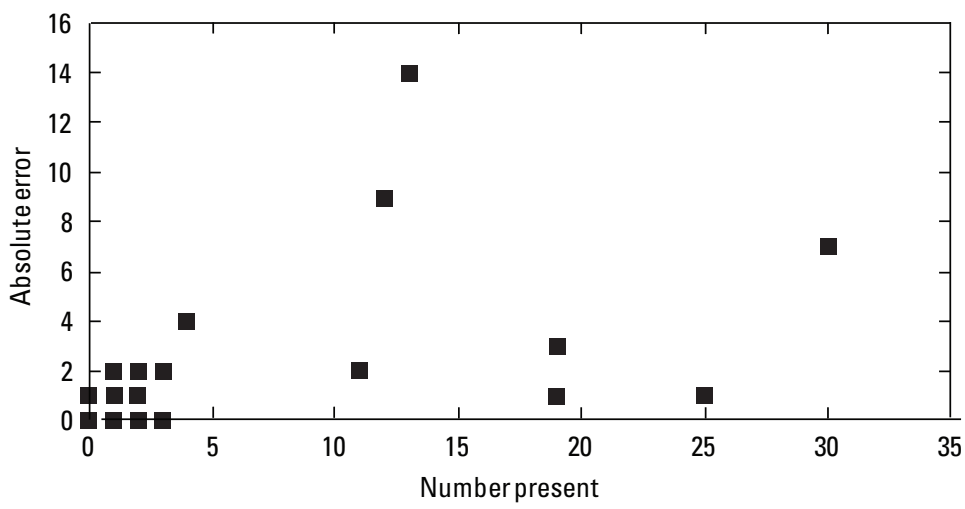

Figure 4. Errors in rapid surveys of intensive plots.

\section{Plot and Stratum Definitions}

Intersecting the fishnet with 9 ha cells on the original study area produced 24,956 cells. Many of the cells were too small to survey. For example, 14percent were less than 1 ha and 29percent were less than 3 ha. Adjusting the plot borders required about two person-months of technician time. In the final layer, all plots were greater than 5 ha and 97 percent were greater than 6 ha. The re-definition of plot boundaries produced 15,028 plots and reduced the number of plots with the best cover type (good-tall) by more than 50percent (from 652 to 319). The procedure also allowed us to make plots in poor habitat — which could be surveyed rapidly — much larger than plots in dense, good habitat.

After the study area boundary was adjusted in 2009, the same process produced 9,491 plots. The density of all focal species combined showed good variation between habitats (table 9). The range in estimated densities was 0.4 to 7.5. Density decreased by approximately 50 percent between each habitat and the next best habitat. Most birds were estimated to be in the low woody habitat type. We tried to find a rule that assigned more birds to the tall woody and/or herbaceous habitats, while maintaining the difference in densities, but the effort was not successful.

\section{Allocation of Effort between Rapid and Intensive Surveys}

The values of $\mathrm{G}_{r}$ and $\mathrm{G}_{i}$ in expression (12) were 10.8 and 0.44 , respectively. With the design used in the pilot study (758 surveys), the predicted optimal numbers of plots were 270 rapid plots and 27 intensive plots, fairly close to the numbers we selected at the beginning of the pilot study (247 and 33). Little loss in precision resulted from considerable variation in the numbers of plots. For example, the relative CV was 0.056 with the optimal design, 0.057 with the actual allocation, and 0.063 with 200 rapid plots and 42 intensive plots. Thus, deviating from the optimal design by 26 percent only increased the relative $\mathrm{CV}$ by 11 percent.

Table 9. Estimated densities and populations sizes in each habitat.

\begin{tabular}{|c|c|c|c|c|c|c|c|}
\hline \multirow[b]{2}{*}{ Plot type } & \multicolumn{3}{|c|}{ Surveyed plots } & \multicolumn{4}{|c|}{ All plots in the study area } \\
\hline & Birds & Plots & $\begin{array}{c}\text { Birds } \\
\text { per plot }\end{array}$ & N plots & $\begin{array}{c}\text { Proportion } \\
\text { of plots }\end{array}$ & $\begin{array}{l}\text { Estimated } \\
\text { birds }\end{array}$ & $\begin{array}{c}\text { Proportion } \\
\text { of birds }\end{array}$ \\
\hline Tall woody & 549 & 73 & 7.5 & 306 & 0.03 & 2,295 & 0.10 \\
\hline Low woody & 249 & 70 & 3.6 & 5,224 & 0.55 & 18,806 & 0.82 \\
\hline Herbaceous & 104 & 58 & 1.8 & 158 & 0.02 & 284 & 0.01 \\
\hline Unvegetated & 13 & 36 & 0.4 & 3,803 & 0.40 & 1,521 & 0.07 \\
\hline Total & 915 & 237 & & 9,491 & 1.00 & 22,907 & 1.00 \\
\hline
\end{tabular}




\section{Evaluation of Sampling Plans and Sample Size Requirements}

We verified the statistical methods and the simulation program by comparing estimates with actual values. We compared estimated mean population size, trend, and variance of the trend estimate (table 10). All were acceptably close to the actual values. So few Vermilion Flycatchers were recorded that we did not simulate their populations.

The panel design had good-to-high power for all species we evaluated (table 11) except Summer Tanagers, which were much less common than the other species (table 5). The design with new plots selected in each year had the highest power except for Summer Tanagers. Surveying the same plot each year yielded lower power especially for Gila Woodpeckers and Summer Tanagers. Surveying the plots every other year, with either the same plots or new plots, yielded substantially lower power (compare designs 4 and 5 in table 11 with designs 2 and 3 ). The analysis of power in relation to sample size showed that surveying 60-80 plots per year is necessary to achieve power exceeding 80 percent for three of the four species (table 12).

\section{Discussion}

This study showed the feasibility of sampling large landscapes using fine-scale, habitat-based stratification. Because habitat patches were small and irregularly shaped, we partitioned the study area into thousands of small polygons suitable for use as survey plots. Although delineating these polygons was time-consuming, we were able to exclude areas not worth surveying and assign different land-cover types to different strata. This allowed us to vary sampling intensity among types and easily obtain separate estimates for different habitats or groups of habitats. More fundamentally, partitioning the study area in this manner produced a rigorous sampling frame that provided a solid foundation for all subsequent steps in designing the sampling plan, conducting the surveys, and analyzing the resulting data. We suspect that many studies using ground-based surveys occur in landscapes where land cover changes frequently in ways that surveyors want to acknowledge in the sampling plan. In such cases, it is difficult to see how land cover could be used as a basis for stratification without adopting procedures similar to the ones we used. We therefore believe the methods demonstrated in this study may have wide applicability in landscape ecology and related fields (for example, forestry, range management, geology).

Table 10. Estimated and actual values for selected parameters used to verify the statistical method and simulation program for four focal species.

\begin{tabular}{|c|c|c|c|c|c|c|c|c|}
\hline Parameter & \multicolumn{2}{|c|}{ Gila Woodpecker } & \multicolumn{2}{|c|}{ Bell's Vireo } & \multicolumn{2}{|c|}{ Yellow Warbler } & \multicolumn{2}{|c|}{ Summer Tanager } \\
\hline Mean population size & 12,103 & 12,138 & 19,497 & 19,510 & 13,509 & 13,511 & 4,050 & 4,009 \\
\hline Variance of trend estimate & 0.00014 & 0.00014 & 0.00008 & 0.00009 & 0.00015 & 0.00015 & 0.00022 & 0.00023 \\
\hline
\end{tabular}

Table 11. Power to detect a 50 percent decline with each of the five designs evaluated.

\begin{tabular}{lcccc}
\hline \multicolumn{1}{c}{ Design } & $\begin{array}{c}\text { Gila } \\
\text { Woodpecker }\end{array}$ & $\begin{array}{c}\text { Bell's } \\
\text { Vireo }\end{array}$ & $\begin{array}{c}\text { Yellow } \\
\text { Warbler }\end{array}$ & $\begin{array}{c}\text { Summer } \\
\text { Tanager }\end{array}$ \\
\hline 1. Panel design & 0.80 & 0.97 & 0.97 & 0.67 \\
2. New plots, every year & 0.97 & 0.99 & 1.00 & 0.61 \\
3. Same plots, every year & 0.66 & 0.87 & 0.91 & 0.59 \\
4. New plots, every other year & 0.68 & 0.73 & 0.80 & 0.51 \\
5. Same plots, every other year & 0.45 & 0.70 & 0.77 & 0.64 \\
\hline
\end{tabular}

Table 12. Power as a function of sample size when new plots are selected each year.

\begin{tabular}{ccccc}
\hline $\begin{array}{c}\text { Number } \\
\text { of plots }\end{array}$ & $\begin{array}{c}\text { Gila } \\
\text { Woodpecker }\end{array}$ & $\begin{array}{c}\text { Bell's } \\
\text { Vireo }\end{array}$ & $\begin{array}{c}\text { Yellow } \\
\text { Warbler }\end{array}$ & $\begin{array}{c}\text { Summer } \\
\text { Tanager }\end{array}$ \\
\hline 40 & 0.74 & 0.89 & 0.89 & 0.24 \\
60 & 0.89 & 0.97 & 0.98 & 0.49 \\
80 & 0.97 & 0.99 & 1.00 & 0.61 \\
100 & 0.99 & 1.00 & 1.00 & 0.74 \\
120 & 1.00 & 1.00 & 1.00 & 0.85 \\
\hline
\end{tabular}




\section{Plot and Stratum Delineation}

The biggest problem in this study was deciding how to partition the study area into plots and the time required to draw the plot borders. We tried several approaches and found that imposing a fish net of cells - with sizes roughly equal to the desired average plot size - was the most practical method. Trying to draw boundaries without the fish net took far too long. In contrast, with practice borders of the fish net, cells could be modified (by drawing new boundaries and then merging polygons) quickly. We initially thought that following natural borders - which would be curved — would be useful but in most cases, such borders were not readily discernible in the field so straight lines, usually oriented north-south or east-west were more useful. These borders were easy to create rapidly using GIS methods. For plots to be surveyed, we digitized the end points and printed the coordinates on the plot maps. They were then entered into GPS units prior to surveys to facilitate navigation during the survey.

As a result of experience in this study and others (Bart and Johnston, in press), we identified several steps in the process of partitioning the study area into plots and incorporated them into an ArcView extension. The extension has 11 tools (table 13). The ArcView extension assumes that a raster land cover layer is available coded with the values that identify unsuitable areas and the land-cover types from which strata will be formed. The first tool (Clip Raster) reduces the size of the raster for faster, subsequent processing. The next tool (Reclassify) produces a new layer identifying unsuitable habitat. The next three tools (Generalize Regions, Region Group, and Convert to Polygons) change the values of isolated pixels to the most common surrounding value and then converts patches of pixels with the same value into polygons. Initial plots are then created with a fish net (Create Plots) and small plots are merged with neighboring, larger ones (Merge Plots). The Merge Plots tool automates the process that we had done manually in this study. The layer produced by Merge Plots must be carefully inspected and numerous changes must be made, but use of Merge Plots reduces the time required dramatically. The next two tools (Plot Habitat, Assign Plot) calculate the amount of each habitat (using the original raster, not the modified ones) in each plot and assigns them to "habitat types" based on user-supplied rules.
The final tools (Plot Areas, Select Plots) produce a table of plot areas and randomly selects a user-specified number of plots from each stratum. The extension and a User's Manual are available from the senior author.

\section{Population of Interest and Sampled Population}

During the study, some regions were inaccessible due to logistic or safety reasons and one region, while technically accessible, was very difficult to reach and appeared to be nearly devoid of birds. For these reasons, a decision was made by the Bureau of Reclamation to exclude five regions from the sampled population. Estimates for the non-surveyed strata can still be made - after the survey has been conducted for several years - probably using a model with habitat and perhaps other covariables, but it will have to be acknowledged that selection bias may occur because the models will be applied to areas outside the areas in which they were developed.

\section{Estimated Densities and Population Sizes}

In many studies, the parameter of interest for surveysnumber of birds present on the plot in this case-is difficult to measure without error. Furthermore, putting an upper limit on the magnitude of measurement error also can be difficult but without such a limit, one cannot establish confidence bounds for the parameter estimates. Many people consider estimates without confidence bounds to be of little value (Williams and others, 2001).

Table 13. Tools in the Sampling Large Landscapes extension for ArcGIS.

\begin{tabular}{ll}
\hline \multicolumn{1}{c}{ Tool } & \multicolumn{1}{c}{ Function } \\
\hline $\begin{array}{l}\text { Clip raster } \\
\text { Reclassify }\end{array}$ & $\begin{array}{l}\text { Clip a raster with a polygon; reduces raster size } \\
\text { Generalize Regions }\end{array}$ \\
Region Group & Converts isolated raster cells to value of the surround cells \\
Convert to Polygons & Assigns unique numbers to contiguous cells of like value \\
Create Plots & Converts regions produced by Region Group to polygons \\
Priority Overlay & Creates a fish net of plots \\
Merge Plots & Intersects two layers retaining polygons from one layer \\
Plot Habitat & Absorbs small plots into surrounding plots \\
Assign Plot & Determines amount of each habitat in each plot \\
Plot Areas & Assigns plots to strata with user-specific rules \\
Select Plots & Produces file with plot areas \\
\hline
\end{tabular}


In this study, our first problem was how to define number of birds "present;" the second problem was obtaining unbiased estimates of the number of birds present. We defined "birds" as territorial birds (and their mates), thus excluding nonterritorial birds. We defined the number of birds present on a plot as (1) the number whose first nest of the season, or territory centroid for non-nesting birds, was within the plot or (2) the sum of the fractions of territories that were within the plot. Using either definition solved a number of problems. The sum of the number present on all plots in the study area was equal to population size. Both definitions made it clear that even if birds were not present when the survey was made, failing to detect them still constituted an error in the survey. Finally, movement by birds did not affect the parameter. When the parameter is defined (often implicitly rather explicitly) as the number present during the survey, movements, especially by wide-ranging species, make it impossible to estimate densities from counts. The only problem with our definition was that surveyors could not be expected to obtain unbiased counts during brief surveys, and it would be difficult to estimate - without additional information - how close, on average, the survey results were to the true number present. For this reason, we carried out much more intensive surveys on a subset of plots. Intensive surveys have been used for many years to obtain accurate counts of territorial birds, and the method has been verified recently in an experimental study (Smith and others, 2009).

In the survey sampling literature, this approach is known as double sampling (Cochran, 1977). It has been widely used in the wildlife field (Eberhardt and Simmons, 1987; Smith, 1995; Bart and Earnst, 2002) and many other disciplines (for example, Wolter, 2007; Schilling and Neubauer, 2009). An important characteristic of double sampling is that the expected value of the estimate is very close to the expected value of the estimates from the intensive plots. From expressions (1) and (5),

$$
E(\hat{\bar{Y}})=E\left(\frac{\hat{\bar{X}}}{\bar{x} / \bar{y}}\right)=E\left(\frac{\hat{\bar{X}}}{\bar{x}} \bar{y}\right) \cong E(\bar{y})=\bar{Y}
$$

the approximation being due to the random variable $\bar{x}$ in the denominator. The bias in $E(\hat{\bar{Y}})$ as an estimate of $\bar{Y}$ diminishes with sample size and generally is negligible when sample size is large enough to achieve useful precision (Cochran, 1977). Double sampling can thus provide accurate estimates even if errors are common on the rapid survey. The precision of the estimator depends on the correlation between rapid and intensive surveys. In our study, the squared correlation coefficient for all species combined was 0.999 . Most values (estimated and actual numbers of birds) were less than 10 but one pair of values was 132,118. Removing this pair of values only decreased the correlation to 0.94 . Thus, rapid and intensive surveys were highly correlated thus, precision of the estimates was high.

\section{Power Analysis}

The power analysis indicated that selecting new plots each year yields the highest precision (table 11). Going to new plots also means that data from new areas are constantly being obtained. This will reveal small areas of high interest, such as areas with Gilded Flickers or Vermilion Flycatchers or areas with rapid population change. Furthermore, if habitat changes, it may be desirable to change stratum assignments for the affected plots. But if the same plots are being re-surveyed, this can be difficult because the surveyed plots will no longer be a simple random sample (due to differences between strata in sampling intensity). For these reasons, it seems wise to select new plots each year. The only disadvantage of this approach is that new plot maps have to be made each year and that clearing trails will be somewhat harder on new plots (although rapid re-growth of vegetation reduces this difference). However, changing the strata might cause difficulty in estimating the standard error of the trend using analytical methods but this is not a problem when using the bootstrap (Shao, 2003).

The sample size analysis (table 12) indicated that surveying 80 plots per year yielded high power to detect a 50 percent decrease in population in 20 years except for Summer Tanagers, which were rarely recorded. Power analysis requires numerous assumptions and thus should not be viewed as providing conclusive results. We therefore recommended that sample size be maintained at 80 surveys per year even though our simulation results suggested that 60 surveys per year would give adequate power for three of the four covered species.

\section{Restoration Areas}

The Bureau of Reclamation requested a long-term sampling plan for the restoration areas. During 2007-10, the number of plots was small, vegetation was low so the plots were easy to survey, and, as a result, all intensive plots were surveyed with intensive methods. This situation, however, will rapidly change as new areas are created and the vegetation in the new areas matures. It is anticipated that several hundred restoration plots will ultimately be available for surveys and that one of the objectives will be estimating the total number of birds (of covered species) in these areas. In earlier discussions, we thought that a panel design might be appropriate. The simulation results (table 11), however, indicate that the panel design is not more efficient than selecting plots each year. Furthermore, revisiting plots would be difficult as the vegetation matures because the plots will change strata. Continuing to re-visit the plots would cause undesirable covariance between results in different strata and additional problems due to complex selection probabilities. It thus now seems preferable to select new plots each year. 
As the methods change from intensive study of a few plots to a sampling design suitable for a large number of plots, the Bureau of Reclamation may need to consider treating the riparian and restoration plots as a single (stratified) population. The restoration plots would be assigned to one or more regions that did not include any riparian plots so estimates for restoration areas would always be easy to obtain. Treating all plots as belonging to one population, however, would mean that separate detection rates would not have to be obtained for the restoration plots. Instead, a few intensive plots would be selected in restoration areas but results from the intensive plots would be combined with intensive plots in riparian areas. This approach probably would require far fewer intensive plots in restoration areas than if restoration areas are treated as a separate population for which a stand-alone estimate of detection rates must be made.

The simulation results reported in this study are not entirely applicable to the restoration plots because once the plots are a few years old they will provide large expanses of tall forest. The plots will thus resemble the plots in our tall woody stratum with few plots of the other habitat types. To investigate sample sizes under these conditions, we ran the simulation program using only the tall woody stratum and with sample sizes (plots surveyed per year) of 40-100. The Bureau of Reclamation may need to detect changes on the restoration areas more quickly than in 20 years so we simulated 35-50 percent population decreases occurring during 10 years. Increases (which are more likely) would be somewhat easier to detect. Results indicated that surveying 80 plots per year would give high power to detect population decreases of 35-50 percent for most species (table 14).

Table 15 provides numbers of intensive and rapid plots for 160-240 surveys per year assuming that intensive plots are each visited eight times and rapid plots are visited twice. If 200 surveys are conducted each year including 8 intensive plots, then 68 rapid plots also could be surveyed. Power as a function of sample size (table 14) indicates that power would be high to detect changes of 35-50 percent occurring during 10 years. Power would be higher to detect larger, short-term changes.

Another design worth considering would be to allocate part of the effort for randomly selected plots and withhold the rest of the available effort for targeted surveys that would not be combined with results from other surveys. For example, if 200 surveys were carried out annually including 4 intensive plots, then, from table 15,60 plots could be randomly selected for the estimation of density and trends and 12 plots (requiring 24 surveys) could be selected non-randomly in areas of high interest. Power would be moderately high yet this design would let managers investigate 12 different plots of high interest each year.
Table 14. Power to detect population declines of 35-50 percent in 10 years in restoration areas.

\begin{tabular}{lclcc}
\hline \multicolumn{1}{c}{ Restoration surveys } & $\begin{array}{c}\text { Gila } \\
\text { woodpecker }\end{array}$ & $\begin{array}{c}\text { Bell's } \\
\text { Vireo }\end{array}$ & $\begin{array}{c}\text { Yellow } \\
\text { Warbler }\end{array}$ & $\begin{array}{c}\text { Summer } \\
\text { Tanager }\end{array}$ \\
\hline Trend & 0.935 & 0.954 & 0.958 & 0.943 \\
10-year decline & 0.49 & 0.38 & 0.35 & 0.44 \\
Power with 40 plots/year & 0.58 & 0.57 & 0.28 & 0.55 \\
Power with 60 plots/year & 0.78 & 0.72 & 0.43 & 0.72 \\
Power with 80 plots/year & 0.88 & 0.85 & 0.53 & 0.84 \\
Power with 100 plots/year & 0.95 & 0.91 & 0.64 & 0.93 \\
\hline
\end{tabular}

Table 15. Potential numbers of intensive and rapid plots.

\begin{tabular}{crcc}
\hline \multirow{2}{*}{$\begin{array}{c}\text { Number of } \\
\text { intensive } \\
\text { plots }\end{array}$} & \multicolumn{3}{c}{ Number of surveys per year } \\
\cline { 2 - 4 } & $\mathbf{2 4 0}$ & $\mathbf{2 0 0}$ & $\mathbf{1 6 0}$ \\
\hline 4 & 104 & 84 & 64 \\
6 & 96 & 76 & 56 \\
8 & 88 & 68 & 48 \\
10 & 80 & 60 & 40 \\
12 & 72 & 52 & 32 \\
\hline
\end{tabular}

\section{A Program to Calculate Power}

The Bureau of Reclamation requested a simple program that could be used to investigate how large a sample of plots would be required to compare densities, for example, between restoration areas created using different methods. The program we produced is called Power.

In statistical analysis, power is the probability of rejecting the null hypothesis when the parameter being estimated has a specified value (usually different from its value under the null hypothesis). The parameter being estimated is often a difference, such as the difference in density (of a given species) in two habitats. In such cases, the value specified by the null hypothesis is usually 0 . The test tells us whether we have convincing evidence that density in the two habitats is different and, if so, which density is larger. Another common parameter is trend, commonly expressed as the rate of change in population size between consecutive years. In this example, the value specified by the null hypothesis is usually 1 meaning no change in population size. The test tells us whether we have convincing evidence that population size is changing and if so whether the population is increasing or decreasing. 
Selecting appropriate levels of power can be difficult because power depends on details of the problem in ways that may be unexpected. For example, the power to detect trends in national surveys is quite low for decreases of as much as 50 percent but may be quite high for a decrease of 75 percent. Managers and others may be uncertain whether they really need to be able to detect a decrease of 50 percent (or less) or whether having high probability of detecting a decrease of 75 percent is sufficient for their purposes.

Power equations specify the relationship between five quantities: the value of the parameter under the null hypothesis $\left(Y_{0}\right)$, the value being assumed for the calculation $\left(Y_{T}\right)$, the standard error $[\operatorname{SE}(y)]$ of the estimate of the parameter, the significance level $(\alpha)$ used in the test, and power, which is usually expressed as $1-\beta$. One way to express the relationships among these variables is

$$
\frac{\left|Y_{0}-Y_{T}\right|}{S E(y)}=Z_{c}+Z_{\beta}
$$

where

$Z \gamma$ is the value of a standard normal deviate exceeded with probability $\gamma$, and

$c=a / 2$ for a two-tailed test or $\alpha$ for a one-tailed text.

The two most common uses of expression (17) are to calculate (1) the power achieved by a stated sample size, or (2) the sample size needed to achieve a desired power. Power is calculated by solving expression (17) for $Z_{\beta}$, from which power can be calculated:

$$
Z_{\beta}=\frac{\left|Y_{0}-Y_{T}\right|}{S E(y)}-Z_{c} .
$$

For example, suppose evaluating expression (18) yields $Z_{\beta}=0.84$. The probability that a standard normal variable exceeds 0.84 is 0.20 so power $(1-\beta)$ is 0.8 .

Estimating the sample size needed to achieve a stated power requires that $\operatorname{SE}(y)$ be expressed as a simple function of sample size,

$$
\operatorname{SE}(y)=C / \sqrt{n}
$$

where $C$ does not depend on sample size. Using expression (19) for $\operatorname{SE}(y)$ and solving expression (17) for $n$ yields

$$
n=\left(\frac{C\left(Z_{c}+Z_{\beta}\right.}{Y_{0}-Y_{T}}\right)^{2}
$$

Suppose that two means, estimated using simple random sampling and with equal sample sizes $(n)$, are being compared in a $t$-test with a pooled variance. Let the sample means be $\bar{y}_{1}$ and $\bar{y}_{2}$ with variances $S_{1}^{2} / n$ and $S_{2}^{2} / n$. In this case, the estimate is $y=\bar{y}_{1}-\bar{y}_{2}$, the value of $y$ under the null hypothesis is 0 , its true value is a specified value $Y_{T}$, and the $\operatorname{SE}(y)$ may be written as

$$
S E(y)=\frac{\left(S_{2}^{2}-S_{1}^{2}\right)^{0.5}}{\sqrt{n}} \equiv \frac{C}{\sqrt{n}}
$$

Inserting the value for $C$ into expression (19) yields

$$
n=\frac{\left(S_{2}^{2}-S_{1}^{2}\right)\left(Z_{c}+Z_{\beta}\right)^{2}}{Y_{T}^{2}} .
$$

As a second example, assume we need to compare the estimated densities of a species in two habitats, 1 and 2 . The formulas for the densities, and their $S E$ s, involve the sample size in each region so it may not be clear how to define "the sample size." One solution is to assume that the same proportion of the sample would be collected in each region even if the overall sample size changed. This would permit us to express $S E(y)$ using the form in expression (21). Advice from a statistician may be needed on how to calculate $C$ in expression (21).

A computer program was written to carry out the power calculations described above. It has a single screen (fig. 5) on which the user provides needed information and receives the power or required sample size. This program may be used to compare densities, investigate habitat relationships, and test to see whether a population size is changing.

\section{Data Management}

During this project, the Coordinated Bird Monitoring Database (CBMD) was evaluated as a repository for the Bureau of Reclamation data at least until Reclamation develops their own database. The CBMD is maintained by the USGS Forest and Rangeland Ecosystem Science Center in Boise, Idaho. Use of the CBMD, including assistance from staff that maintain the database, is available to all interested parties free of charge. The CBMD also could be used to store data from other surveys conducted by Reclamation, so we describe it in general terms in this section.

The CBMD is a "counts" and "projects" database. The database stores counts, meaning that times and places were selected for surveys and objects (such as birds) were counted during the survey. Although the CBMD primarily is used for counts of birds, counts of other objects could be stored in the CBMD. The CBMD stores project-level data. Variables in the database are not pre-determined; users can store any data 
1. Enter the following quantities (more info)

One-tailed or two-tailed test(more info)?

One-tailed

c Two-tailed

Significance level(more info)?

0.0010 .10

0.010 .15

( . $05 \quad 0.20$

Value of the parameter under the null hypothesis, $Y_{0}$ (more info)?

Assumed true value of the parameter, $Y_{T}$ (more info)?

2. To get power:

Enter the SE of the estimate, SE(y) (more info)

Power

3. To get sample size:

Enter a constant, $C$, that satisfies

$S E(y)=\frac{C}{\sqrt{n}}$ (more info)

Enter the power you want to achieve (more info)

Sample size
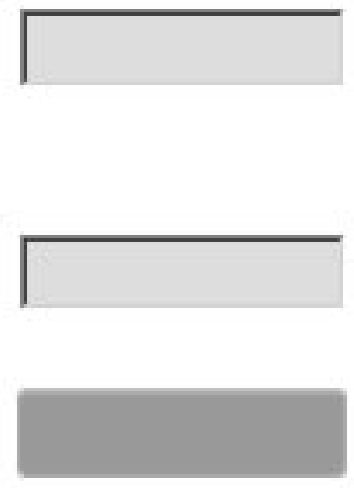

\section{Help/About}

Figure 5. Screen in the program Power used to enter data and obtain estimated power or sample size. 
that they have collected. The CBMD consists of three primary tables: (1) a "Pedigree" table that describes the sampling plan used to select the places and times for counts; (2) a "Surveys" table that describes information about each survey; and (3) a "Counts" table that stores information collected about each object recorded (for example, species, number). Every dataset stored in the CBMD has a data "owner." The owner decides what data to store in the CBMD and what level of access to the data is provided to others. We use a five-level system of access designed by the Cornell Laboratory of Ornithology. Decisions about access and distribution of the data are always made by the data owner, never by CBMD staff.

Project leaders interested in using the CBMD contact the CBMD staff for assistance in designing their study as well as storing the study results. If requested, CBMD staff can produce Microsoft $\mathrm{C}$ Excel spreadsheets for data entry. The spreadsheet usually resembles the field survey form and contains all variables entered on the form. The user enters data and then clicks a "Submit" button, which activates error checking routines. If no errors are found, the data are re-arranged into a format suitable for inclusion in the "Pedigree," "Surveys," and "Counts" tables and are then appended to these tables. Periodically, the spreadsheet is emailed to the CBMD staff who upload the data into the CBMD (for example, at the end of each field season).

Users can access the data via the Internet. They sign on, choose their program, and enter a password if needed. The variables in the program are then displayed and the user can define a query by selecting any values on any subset of the variables. The user also can ask for either a bulk download of all records meeting their query or can ask for estimated densities and population sizes for any "level" in the sampling plan. For example, if a user signed on to the Intermountain West Aquatic Bird Survey, the user could ask for estimated means and totals (for any subset of records) for each State, each Bird Conservation Region, each "Bird Conservation Subregion" (polygons formed by intersecting a BCR and States/Provinces layers), or each site. Results would be aggregated automatically at whichever level the user selected. For example, if the user asked for densities by State, then means for each State covered by the program would be calculated and presented to the user. This ability to aggregate results in a statistically rigorous fashion, even though many different sampling plans were followed at different sites is, to the best of our knowledge, unique among databases.

The CBMD is a node of the Avian Knowledge Network at Cornell University and CBMD staff periodically uploads core variables to it. CBMD staff prepare metadata (using the full Federal Geospatial Data Committee standards and the reduced Natural Resource Monitoring Partnership set of variables) and submit them to the appropriate permanent repositories maintained by the government and by the Cornell Laboratory of Ornithology. We believe the CBMD may provide a useful long-term repository for data from the riparian bird survey.

\section{Summary}

This study both developed rigorous methods for monitoring riparian birds on the Lower Colorado River and illustrated an approach for surveying large landscapes using small-scale stratification that may have wide applicability. The study introduced novel methods in three areas: GIS methods to partition the landscape into plots and assign them to strata, field methods for use when point and line transect methods are impractical or give unreliable results, and analytic methods and data management tools including simulation methods to estimate power, an analysis program for data collected using double sampling, and a database that holds virtually any form of "count" data. Taken together these methods provide a comprehensive toolkit for the Bureau of Reclamation and other groups interested in surveying large landscapes. The methods are currently being used in northern Canada, Nevada, Arizona, and Mexico in addition to the Lower Colorado River study site. Experience in these areas suggest the approach has wide applicability but also make clear that variations on the general theme are often needed. For example, in the arctic much larger study areas are surveyed so adjusting plot borders by hand, as done in this study, is not feasible and automated methods must be used. A more complex sampling plan is also needed in the arctic, which substantially complicates the analysis. Program DS, however, includes the needed statistical routines. In Arizona, the habitat to be surveyed (riparian areas) had not been mapped and was too extensive to digitize completely so a double sampling method was developed to estimate stratum sizes. Our impression is that each new study will present new challenges but that the general approach has sufficient flexibility to accommodate most needs for sampling large landscapes.

\section{Acknowledgments}

We appreciate the assistance of numerous surveyors who carried out the surveys and the comments of John Swett, Theresa Olson, Chris Dodge of the Bureau of Reclamation; Elizabeth Ammon and Ann Manning of Great Basin Bird Observatory; two anonymous reviewers; and especially of Linda Rogers of the USGS Publishing Network. Funding for the study was provided by the Bureau of Reclamation and the U.S. Geological Survey. 


\section{References Cited}

Alldredge, M.W., Pacifici, K., Simons, T.R., and Pollock, K.H., 2008, A novel field evaluation of the effectiveness of distance and independent observer sampling to estimate aural avian detection probabilities: Journal of Applied Ecology, v. 45, p. 1349-1356.

Alldredge, M.W., Pollock, K.H., Simons, T.R., and Shriner, S.A., 2007a, Multiple-species analysis of point count data: A more parsimonious modeling framework: Journal of Applied Ecology, v. 44, p. 281-290.

Alldredge, M.W., Simons, T.R., and Pollock, K.H., 2007b, Evaluation of distance measurement errors in auditory avian point count surveys: Journal of Wildlife Management, v. 71, p. 2759-2766.

Anderson, B.W., and Ohmart, R.D., 1976, Vegetation type maps of the lower Colorado River from Davis Dam to the southerly international boundary: U.S. Department of the Interior, Bureau of Reclamation, Boulder City, Nevada.

Anderson, B.W., and Ohmart, R.D., 1984, Vegetation community type maps, lower Colorado River. U.S. Department of the Interior, Bureau of Reclamation, Boulder City, Nevada.

Bart, J., Burnham, K.P., Dunn, E.A., Frances, C.M., and Ralph, C.J., 2004, Goals and strategies for estimating trends in landbird abundance: Journal of Wildlife Management, v. 68 , p. 611-626.

Bart, J., and Earnst, S.L., 2002, Double sampling to estimate density and population trends in birds: Auk, v. 119, p. 36-45.

Bart, J., and Johnson, V., in press, Arctic shorebirds in North America: results of a ten-year monitoring program: Studies in Avian Biology.

Bibby, C.J., Burgess, N.D., Hill, D.A., and Mustoe, S., 2000, Bird census techniques: New York, Academic Press.

Braun, C.E., ed., 2005, Techniques for wildlife investigations and management, sixth edition: Bethesda, Maryland, The Wildlife Society.

Buckland, S.T., Anderson, D.R., Burnham, K.P., Laake, J.L., Borchers, D.L., and Thomas, L., 2001, Introduction to Distance Sampling: Oxford, United Kingdom, Oxford University Press.

Buckland, S.T., Anderson, D.R., Burnham, K.P., Laake, J.L., Borchers, D.L., and Thomas, L., eds., 2004, Advanced Distance Sampling: Oxford, United Kingdom, Oxford University Press.
Bureau of Reclamation, 2006a, Lower Colorado River Multi-Species Conservation Program, Final Implementation Report, Fiscal Year 2007 Work Plan and Budget, Fiscal Year 2005 Accomplishment Report, August 16, 2006: Boulder City, Nevada.

Bureau of Reclamation, 2006b, Lower Colorado River Multi-Species Conservation Program, Draft Final Science Strategy, August 4, 2006: Boulder City, Nevada.

Bystrak, D., 1981, The North American Breeding Bird Survey, in Ralph, C.J., and Scott, J.M., eds., Estimating numbers of terrestrial birds: Studies in Avian Biology, no. 6, p. 34-41.

Cochran, W.G., 1977, Sampling techniques: New York, John Wiley \& Sons.

Droege, S., 1990, The North American Breeding Bird Survey, in Sauer, J.R., and Droege, S., eds., Survey designs and statistical methods for the estimation of avian population trends: U.S. Fish Wildlife Service Biological Report 90, no. 1, p. 1-4.

Eberhardt, L.L., and Simmons, M.A., 1987, Calibrating population indices by double sampling: Journal of Wildlife Management, v. 51, p. 665-675.

Efron, B., and Tibshirani, R.J., 1993, An introduction to the bootstrap: New York, Chapman and Hall.

Farnsworth, G.L., Pollock, K.H., Nichols, J.D., Simons, T.R., Hines, J.E., and Sauer, J.R., 2002, A removal method for estimating detection probabilities from point-count surveys: Auk, v. 119, p. 414-425.

Great Basin Bird Observatory, 2009, Nevada Bird Count: Intensive area searches and spot-mapping: Unpublished report available from the Great Basin Bird Observatory.

Nichols, J.D., Hines, J.E., Sauer, J.R., Fallon, F.W., Fallon, J.E., and Heglund, P.J., 2000, A double-observer approach for estimating detection probability and abundance from point counts: $A u k$, v. 117, p. 393-408.

Rich, T.D., Beardmore, C.J., Berlanga, H., Blancher, P.J., Bradstreet, M.S.W., Butcher, G.S., Demarest, D.W., Dunn, E.H., Hunter, W.C., Iñigo-Elias, E.E., Kennedy, J.A., Martell, A.M., Panjabi, A.O., Pashley, D.N., Rosenberg, K.V., Rustay, C.M., Wendt, J.S., and Will, T.C., 2004, Partners in Flight North American Landbird Conservation Plan: Ithaca, New York, Cornell Lab of Ornithology.

Rosenberg, K.V., Ohmart, R.D., Hunter, W.C., and Anderson, B.W., 1991, Birds of the Lower Colorado River valley: Tucson, Arizona, University of Arizona Press. 
Sauer, J.R., Hines, J.E., and Fallon, J., 2008, North American breeding bird survey, results and analysis, 1966-2007: Laurel, Maryland, Patuxent Wildlife Research Center, Laurel, Maryland.

Schilling, E.G., and Neubauer, D.V., 2009, Acceptance sampling in quality control: New York, CRC Press, Chapman and Hall.

Shao, J., 2003, Impact of the bootstrap on sample surveys: Statistical Science, v. 18, p. 191-198.

Skagen, S., Bart, J., Andres, B., Brown, S., Donaldson, G., Harrington, B., Johnston, V., Jones, S.L., and Morrison, R.I.G., 2003, Monitoring the shorebirds of North America: towards a unified approach: Wader Study Group Bulletin 100, p. 102-104.

Smith, G.W., 1995, A critical review of the aerial and ground surveys of breeding waterfowl in North America: U.S. Fish and Wildlife Service, Technical Report, Laurel Maryland.

Smith, P.A., Bart, J., Lanctot, R.B., McCaffrey, B.J., and Brown, S., 2009, Detection probability of nests and implications for survey design: Condor, v. 111, p. 414-423.
Sutherland, W. J., 2006, Ecological census techniques: Cambridge, United Kingdom, Cambridge University Press.

Thompson, W.L., White, G.C., and Gowan, C., 1998, Monitoring Vertebrate Populations: New York, Academic Press.

Urquhart, N.S., and Kincaid, T.M., 1999, Designs for detecting trend from repeated surveys of ecological resources: Journal of Agricultural, Biological, and Environmental Statistics, v. 4, p. 404-414.

U.S. Fish and Wildlife Service, 2009, Waterfowl population status, 2009: U.S. Department of the Interior, Washington, D.C.

Williams, B.K., Nichols, J.D., and Conroy, M.J., 2001, Analysis and management of animal populations: New York, Academic Press.

Wolter, K.M., 2007, Introduction to variance estimation, $2^{\text {nd }}$ edition: New York, Springer-Verlag. 
Publishing support provided by the U.S. Geological Survey Publishing Network, Tacoma Publishing Service Center

For more information concerning the research in this report, contact the Director, Forest and Rangeland Ecosystem Science Center

U.S. Geological Survey

777 NW 9th Street

Corvallis, Oregon 97330

http://fresc.usgs.gov 
$\frac{9}{7}$

을

章

ए

$\infty$

를

끙

윽

증

ํํำ

함

옿

5

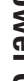

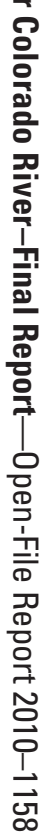

